98 Magma

\title{
Poemas de OSSIAN OU 0 PRIMITIVISMO COMO FORMA
}

Thiago Rhys Bezerra Cass*

\section{Resumo}

Neste ensaio, discutirei como James Macpherson, em suas falsas traduções dos Poemas de Ossian, logrou criar um novo gênero literário: o primitivismo. Tal gênero, forjado numa conciliação entre a lírica e a épica, apresentou-se, aos leitores do século XVIII, como uma comunhão plena e definitiva entre forma, linguagem, temas, valores encerrados na obra e o tempo em que se passa a história. Discuto, ainda, como a formação desse novo gênero literário esteve intimamente relacionada à situação social, política e cultural da Escócia do século XVIII.

\section{Abstract}

In this essay, I will explain how James Macpherson, in his fake translations of the "Poems of Ossian", was able to create a new literary genre: primitivism. This genre, born of the meeting of epic and lyrical poetry, was presented to the readers of the eighteenth century as a complete and definitive fusion of form, language, themes, of the values engraved within the text, and of the age in which the story took place. I will also discuss how the development of this new literary genre was intimately related to the social, political and cultural background of eighteenthcentury Scotland.

\author{
Palavras-chave \\ Ossian; \\ Primitivismo; \\ Escócia; \\ Século XVIII.
}

\author{
Keywords \\ Ossian; \\ Primitivism; \\ Scotland; \\ Eighteenth \\ Century.
}

* Mestrando em Teoria Literária e Literatura Comparada (DTLLC-FFLCH-USP). Bolsista do CNPq. 
I shall conclude this general account with some remarks on four of the principal works of poetry in the world, at different periods of history - Homer, the Bible, Dante, and, let me add, Ossian.

(Hazlitt, On Poetry in General, 1818)

primitivismo literário nasceu como uma declaração de repulsa às transformações sociais e políticas ocorridas a partir da segunda metade do século XVIII. É óbvio que existem obras que expressam descontentamento com os rumos da civilização desde o final da Idade Média e, além disso, com um quê de pedantismo, é possível tomar a poesia bucólica clássica como uma espécie de precursora do gênero em questão. Contudo, não se encontrará em nenhuma dessas obras algo que tenha o condão de explicitar as peculiaridades do primitivismo literário. A poesia de Spenser, por exemplo, é primitiva tão somente no que concerne ao vocabulário arcaizante e à idealização da ética medieval. A forma de The Faerie Queene tem, por assim dizer, alguma autonomia em face da história que nos é contada; é confessadamente articulada de acordo com as necessidades e preceitos estéticos do tempo em que vivia o autor - e não se apresenta como veículo de uma sensibilidade já não mais existente. ${ }^{1}$ Quase dois séculos depois, Young, em suas Conjectures on Original Composition, ainda zombaria, porque ridiculamente artificiais, das tentativas de seus contemporâneos de recriar aquela que seria a dicção das assim chamadas "composições originais". ${ }^{2}$ Com efeito, é somente com o advento dos Poemas de Ossian - as falsas traduções de antigas baladas celtas empreendidas pelo escocês James Macpherson - que se estabelecerá, para os leitores dos séculos XVIII e XIX, na chamada literatura primitivista, uma comunhão plena e definitiva entre forma, linguagem, temas, valores encerrados na obra e no tempo em que se passa a história.

${ }^{1}$ Sobre a prosódia de Spenser, ver SAINTSBURY, G. A History of English Prosody: From the Twelfth Century to the Present Day. 2. ed. London: Macmillan, 1923, p. 350-69, vol. I.

${ }^{2}$ YOUNG, E. Conjectures on Original Composition in a Letter to the Author of Sir Charles Grandison. London, 1759, p.11-2. 
Nem mesmo na essencialmente antimoderna lírica do pré-romantismo, à qual muitos costumam vincular as traduções de Macpherson, é possível encontrar uma nova forma literária apta a dar completa vazão ao que então se chamava de primitive manners, a despeito da incessante busca de Thomson e seus contemporâneos por uma expressividade que transpusesse o comedimento da poesia augustana e, com isso, exaltasse o sentimental e o patético. Conquanto a poesia se torne, de fato, mais retórica e a sua linguagem mais pitoresca e figurativa, não se abandona a estrutura métrica que rege a poesia inglesa desde Chaucer: o sistema acentual-silábico majoritariamente com ênfase iâmbica, salvo pontuais exceções (geralmente inversões trocaicas ou equivalências anapésticas) exigidas pela lógica interna da obra. Um exemplo eloquente desse fenômeno ocorre com o famoso poema The Bard, de Thomas Gray, de $1757,{ }^{3}$ em que a linguagem extravagante atribuída aos antigos celtas e a liberdade expressiva e o furor poeticus contidos na ode pindárica convivem de maneira um tanto desconfortável com o ritmo regular e bem marcado de um versejador extremamente talentoso:

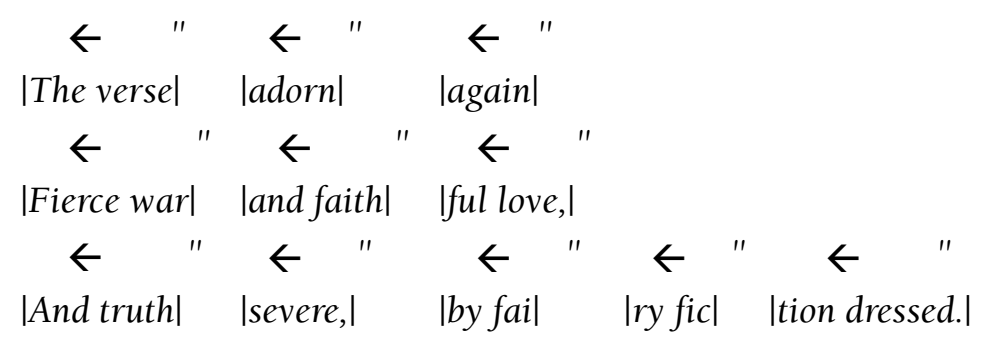

Subsiste, aqui, um conjunto de convenções que, por si mesmas, atribuem valor poético à obra e vinculam-lhe a um tesouro de saberes sobre as especificidades $e$ os limites da poesia. Tem-se, portanto, uma obra que se declara, ainda que a contragosto, ser fruto de um processo criativo eminentemente racional, apto a adequar a elocução poética aos preceitos legados pela tradição. Falta aos antecessores de Macpherson a capacidade de permitir que sua poesia se apresente como fruto de um espírito selvagem, inculto e, acima de tudo, espontâneo - essa espontaneidade que, nos Poemas de Ossian, recusa uma filiação clara a um gênero literário específico, porquanto forja uma conciliação entre a épica e a lírica, em que o modo narrativo é constantemente subjugado, interrompido ou transfigurado pelo monólogo lamentoso do eu. ${ }^{4}$ Como já percebia Hugh Blair em $1765,{ }^{5}$ há um compromisso

${ }^{3}$ Três anos antes da publicação, por parte de Macpherson, dos primeiros Fragments of Ancient Poetry.

${ }^{4}$ Para uma análise minuciosa das inadequações do Fingal aos preceitos da épica clássica, ver STAFFORD, F. The Sublime Savage: James Macpherson and the Poems of Ossian. Edinburgh: Edinburgh University, 1988, p. 133-49, e, principalmente, BYSVEEN, J. Epic Tradition and Innovation in James Macpherson's Fingal. Uppsala: Acta Universitatis Upsaliensis, 1982, passim.

${ }^{5}$ BLAIR, H. A Critical Dissertation on the Poems of Ossian, the Son of Fingal. In: MACPHERSON, J. The Poems of Ossian and Related Works. Edinburgh: Edinburgh University, 2003, p. 399. Ver também as observações de SAINTSBURY, G. A History of English Prosody: From the Twelfth Century to the Present Day. 2. ed., London: Macmillan, 1923, p. 43-6, vol. III. 
muito evidente nas (falsas) traduções de Macpherson entre cadência e liberdade de estruturação narrativa, num arranjo em que a história, para evoluir, depende (mas não de maneira absoluta) da construção - e das variações - do ritmo da obra. Efetivamente, é o Ossian que faz com que a literatura de temas primitivistas converta-se naquilo que o público do século XVIII acreditava ser a manifestação literária de um povo primitivo.

Embora ainda não se tivesse logrado formular uma dicção que denotasse a espontaneidade do gênio natural, a lírica pré-romântica (Collins, Akenside etc.) foi pródiga no emprego de topoi que indicassem a sensibilidade - e não a razão como fonte exclusiva das faculdades poéticas. Assim, abundam poemas dispostos a se apresentar como inspirados pela comunhão do poeta com (ou onde se encontra) aquilo que Burke definiria como o sublime - em florestas farfalhantes, à hora do crepúsculo ou sob a invocação de uma harpa eólica. Tais topoi se fazem largamente presentes nos poemas atribuídos a Ossian. ${ }^{6}$

Se as fontes do sentimentalismo que perpassa o primitivismo ossiânico encontram-se nos escritos pré-românticos, é nos estudos dos clássicos que se entreveem aquelas que seriam as características distintivas do gênio natural. Efetivamente, é impossível compreender o fenômeno ossiânico sem o recurso às discussões então correntes sobre a singularidade - e "inimitável beleza" - da poesia homérica. O ponto central de tais discussões era como conciliar os evidentes méritos literários da Ilíada e da Odisseia com a constatação de que esses épicos fugiam - e muito das normas do decoro e do bom gosto. Na Grã-Bretanha, os primeiros pensadores de relevo a esboçar algum tipo de solução para essa vexata quaestio foram Joseph Addison e Alexander Pope, nomes em cujas obras se encarnam as maiores aspirações do Classicismo inglês. Addison, num breve artigo de 1711 para o Spectator, ${ }^{7}$ estabelece um contraponto entre o natural genius e o refined genius: ${ }^{8}$ o primeiro se distingue por sua força e capacidade de compor símiles e metáforas, hauridas da observação direta da natureza; o segundo, por sua vez, concebe a poesia como uma arte essencialmente racional e imitativa, produto de longa reflexão diante dos exemplos legados por seus antecessores. No longo prefácio à sua tradução da Ilíada, Pope, por sua vez, falará da existência de um fogo nos poemas de Homero, resultante de uma inventividade ainda não constrita por quaisquer convenções estéticas. ${ }^{9}$

Em ambas as reflexões há uma espécie de historicismo, ainda pouco articulado, porém capaz de compreender que aquilo que se denominava de gênio poético não era apartado das circunstâncias históricas, conquanto tais circunstâncias fossem percebidas de uma maneira um tanto vaga ou idealizada. Esse tipo de abordagem da poesia antiga foi levado às últimas consequências pelo viajante Robert Wood e pelo erudito Thomas Blackwell. Este último, professor de Macpherson na Universidade de Aberdeen, elaborou seu Enquiry into the Life and Writings of

\footnotetext{
${ }^{6}$ TODD, J. Sensibility: an Introduction. Methuen: London and New York, 1986, p. 54.

${ }^{7}$ MORLEY, H. The Spectator. London: Routledge, 1891, p. 546-49, vol. I.

${ }^{8}$ Seus máximos representantes são, respectivamente, Homero e Virgílio.

${ }^{9}$ The Iliad of Homer Translated by Mr. Pope. London, 1715 (Prefácio sem paginação).
} 
Homer sob a seguinte premissa: a superioridade da épica de Homero só poderia ser explicada se se estudasse, antes, a Fortuna do aedo, a qual permitira o florescimento de seu gênio literário.

Dizia Blackwell que as composições literárias dependem, em grande parte, das oportunidades - dos "originais" a serem imitados - oferecidas pela Fortuna do indivíduo, a qual viria a ser um conjunto de circunstâncias de várias ordens (política, climática, geográfica ou religiosa), e que permitiriam - ou não - o desenvolvimento de certas faculdades do espírito humano. De tal maneira, a poesia dos antigos seria dotada de uma qualidade que inexiste naquela feita pelos modernos: a presença da Verdade. ${ }^{10}$ Para Blackwell, a vida rústica e guerreira dos antigos fez com que seu caráter se devotasse exclusivamente ao culto da virtude e à feitura de atos heroicos, que são os grandes temas da poesia épica; suas criações poéticas não precisavam se socorrer da imaginação (e de alusões a anões, donzelas infelizes, penhascos horríveis e palácios encantados), a qual é incapaz de conferir às descrições da natureza um efeito estilístico mais poderoso ou eficiente que aquele proporcionado pela Verdade. Diante disso, a ideia de que o poeta é uma entidade autônoma, que interpreta a natureza de modo unilateral, é posta em questão: tão importante quanto a capacidade do poeta de apreender a essência do mundo que o cerca é a influência daquilo que está ao seu redor na formação de sua sensibilidade artística e na organização interna de sua obra. ${ }^{11}$

Macpherson perceberia de maneira bastante arguta que a análise de Blackwell tinha uma dúplice implicação: de um lado, expunha a falsidade - ou artificialidade - da literatura de seus contemporâneos, atida a procedimentos estéticos completamente apartados do mundo ou dos sentimentos; de outro, tornava extensivos à sociedade em que vivera o poeta os méritos - ou defeitos - de sua obra. Assim, nos inúmeros ensaios introdutórios, glosas e breviários explicativos ${ }^{12}$ que recheiam os Poemas de Ossian - em que estariam, juntamente com os escritos de Blair e Cesarotti, as grandes, por assim dizer, referências teóricas do primitivismo -, vale-se das lições de Blackwell e faz com que a apreciação da literatura primitiva (ou primitivista) seja mediada por uma discussão acerca das virtudes específicas das sociedades ditas não polidas. ${ }^{13}$ Com isso, numa Escócia

${ }^{10}$ BLACKWELL, T. An Enquiry into the Life and Writings of Homer. London, 1735, p. 215 e p. 285-86.

${ }^{11}$ Sobre a importância das teorias de Blackwell para o Ossian, ver LACERDA, S. Metamorfoses de Homero: História e Antropologia na Crítica Setecentista da Poesia Épica, Brasília: UnB, 2003, p. 157231 (especialmente p. 218-21); HAUGEN, K.L. Ossian and the Invention of Textual History. Journal of the History of Ideas, v. 59, n. 2, p. 309-27, abr. 1998 e KERSEY, M. Addison's Indian, Blackwell's Bard and the Voice of Ossian. History of European Ideas, v. 31, n. 2, p. 265-75, set. 2005.

12 Todos eles necessários para se afastar as acusações de fraude.

${ }^{13}$ Veja-se, por exemplo, o comentário de William Duff sobre a poesia ossiânica: In examining the merits of this divine Poet we shall [...] endeavour to shew that the essential characteristics of elevated and original Genius [...] are found in the Poems of Ossian, in as high a degree as was consistent with the manners of the age and the state of society in which he lived and with the subjects and design of his compositions. DUFF, W. Critical observations on the writings of the most celebrated original geniuses in poetry. London, 1770 , p. 64-7. 
semisselvagem e decadente, converte a literatura (ou melhor: a sua literatura) numa questão nacional:

\begin{abstract}
The nobler passions of the mind never shoot forth more free and unrestrained than in these times we call barbarous. That irregular manner of life, and those manly pursuits from which barbarity takes its name, are highly favorable to a strength of mind unknown in polished times. In advanced society the characters of men are more uniform and disguised. The human passions lie in some degree concealed behind forms, and artificial manners; and the powers of the soul, without opportunity of exerting them, lose their vigor. The times of regular, and polished manners, are therefore to be wished for by the feeble and weak in mind. An unsettled state, and those convulsions which attend it, is the proper field for an exalted character, and the exertion of great parts. Merit there rises always superior; no fortuitous event can raise the timid and mean into power. To those who look upon antiquity in this light, it is an agreeable prospect; and they alone have real pleasure in tracing nations to their source. ${ }^{14}$
\end{abstract}

Após a publicação dos Poemas de Ossian, esse tipo de abordagem, em que se entretecem juízos literários e mistificação histórica, tornou-se corrente entre os homens de letras do Iluminismo e do Romantismo escoceses. Faz-se presente nas obras de Ferguson, Blair e, ainda que de maneira mais elaborada, Scott. Efetivamente, o autor de The Lay of the Last Minstrel se valeu largamente dos chamados modos ossiânicos para caracterizar seus heróis (seja nos romances, seja nas baladas) da Escócia pré-moderna, num expediente que consistia, simultaneamente, numa técnica para atribuir verossimilhança histórica às suas personagens e, de modo mais velado, num elogio a uma sociedade que estava deixando de existir. ${ }^{15}$

De fato, nos escritos de Macpherson e dos entusiastas do Ossian está expresso o mal-estar da época defronte das profundas transformações por que vivia a Escócia. Representam uma tentativa desesperada de preencher um vazio causado, primeiramente, pelo Ato de União dos Parlamentos, de 1707, e, depois, pelas medidas tomadas por Londres por ocasião da vitória sobre o Levante Jacobita de 1745 .

A Escócia foi o terceiro país do mundo a fazer a transição completa de uma economia feudal para uma economia capitalista. Ao contrário do que ocorreu na Inglaterra e nas Províncias Unidas, contudo, tal transição não se deu de maneira progressiva, ao longo dos séculos; foi, em grande parte, decorrente de reformas liberalizantes impostas unilateralmente pelo poder central.

$\mathrm{Na}$ Inglaterra, a Revolução Gloriosa teve um sentido eminentemente progressista, em que triunfaram as liberdades burguesas sobre o Absolutismo. $\mathrm{Na}$ Escócia, ao contrário, a deposição dos Stuart trouxe consigo um retrocesso às relações feudais de poder, uma vez que inexistia, no país, uma classe que se con-

${ }^{14}$ MACPHERSON, J. A Dissertation. The Poems of Ossian and Related Works. Edinburgh: Edinburgh University, 2003, p. 205.

${ }^{15}$ Ver MANNING, S. "Ossian, Scott and Eighteenth-Century Scottish Nationalism". Studies in Scottish Literature, v. 47, p. 39-54, 1982. Sobre a maneira como Scott atribuía verossimilhança histórica às suas personagens, ver LUKÁCS, L. The Historical Novel. Translated by Hannah and Stanley Mitchell. Lincoln and London: University of Nebraska, 1983, p. 30-54. 
trapusesse aos senhores de terras. Reforça-se, com isso, a submissão dos camponeses aos lairds (sic), a quem deviam serviço militar e sob a jurisdição dos quais estavam subordinados. Esse sistema de lealdades era ainda mais intenso na região dos Highlands, onde havia o sistema de clãs, que estabelecia um liame muito mais sólido entre classes, porquanto proporcionava aos camponeses uma sensação de pertencimento a um grupo. Era, de fato, uma sociedade com marcados traços tribais.

Ainda que esse anacrônico arranjo social tenha sido ratificado pela União dos Parlamentos, não tardou para que ele se mostrasse completamente inadequado às novas realidades econômicas decorrentes dessa mesma União. De fato, a produção agrícola escocesa era dispendiosa e ineficiente, incapaz de competir com a das fazendas da burguesia rural inglesa e de atender às necessidades do grande mercado consumidor a que a Escócia se integrara. Nos Highlands, esse quadro era ainda mais dramático, pois os lairds estavam formalmente ligados aos membros de seu clã, e não poderiam dispensá-los facilmente com o intuito de tornarem-se empreendedores agrícolas. Arruinados, afiguravam-se-lhes duas saídas, ambas calcadas em seus ampliados poderes estamentais: ou aumentar a exação ou sublevar-se contra a nova ordem. Muitos adotaram a primeira alternativa, mas a arrecadação chegara ao limite em muitos lugares, e houve tumulto e revolta. A opção sediciosa, por sua vez, esteve presente ao longo de quase toda a primeira metade do século XVIII, até que Londres, após o fracasso do Levante de 1745, adotasse medidas destinadas a remover definitivamente as instituições e lealdades que, de um lado, garantiam o imenso poder militar dos senhores de terras e, de outro, sufocavam a modernização capitalista da agricultura e da sociedade escocesas. ${ }^{16}$

Os Highlands foram dominados militarmente, e a jurisdição dos chefes dos clãs foi transferida para juízes de paz, ministros da Igreja Anglicana e para os comandantes militares ali instalados. A língua gaélica foi proibida e os clãs, desfeitos - e muitos de seus chefes - dentre os quais se inclui Ewan Macpherson de Cluny, ${ }^{17}$ pai do tradutor do Ossian - foram presos ou perseguidos. Construíram-se estradas de modo a integrar os habitantes das montanhas à vida econômica do sul.

As medidas impostas pelos ingleses em pouco tempo alteraram por completo o modo de vida dos highlanders. Anos depois, quando Boswell e o Doutor Johnson fizeram sua famosa viagem pela região, quase nada encontraram das antigas práticas das quais, por muito tempo, os escoceses das terras altas se orgulharam. Segundo Johnson, os highlanders em nada diferiam dos habitantes do sul do país, a não ser pelo fato de serem mais pobres, atrasados e ignorantes. E os bardos estavam extintos há muito tempo. ${ }^{18}$

${ }^{16}$ Vejam-se os artigos de N. Davidson sobre as transformações ocorridas na economia da Escócia: DAVIDSON, N. The Scottish Path to Capitalist Agriculture 1: From the Crisis of Feudalism to the Origins of Agrarian Transformation (1688-1746). Journal of Agrarian Change, v. 4, n. 3, p. 227-68, julho 2004 e DAVIDSON, N. The Scottish Path to Capitalist Agriculture 2: The Capitalist Offensive (1747-1815). Journal of Agrarian Change, v. 4, n. 4, p. 411-60, outubro 2004.

${ }^{17}$ Seu clã é mencionado, aliás, por Robert Louis Stevenson em Kidnapped.

${ }_{18}^{18}$ JOHNSON, S. A Journey to the Western Islands of Scotland. London, 1816, p. 153-54. 
Ao extirpar o elemento gaélico da cultura escocesa e tentar integrá-la definitivamente à ordem inglesa, o governo de Londres tornou ainda mais explícitas as diferenças existentes entre os dois povos. Em todos os campos, a inferioridade dos escoceses defronte dos ingleses era evidente. Até mesmo no plano literário: por exemplo, das cinquenta e duas Vidas escritas por Johnson acerca dos grandes escritores de língua inglesa, apenas duas se referiam a autores escoceses, diante de quarenta e cinco ingleses e quatro irlandeses, além de um galês.

Como resposta que era ao estado de desorientação dos escoceses (em especial dos highlanders) causado tanto pelo desaparecimento de valores semitribais e consequente introdução do dinheiro como mediador das relações intersubjetivas quanto pela certeza da perenidade do domínio estrangeiro, a poesia de Ossian não poderia se configurar sob as formas literárias até então existentes. Precisava ser uma resposta que, por um lado, negasse os valores dos ingleses e que, por outro, não lhes fosse esteticamente incompreensível. Era necessário que se gravassem, simultaneamente, num só tecido literário, a exaltação do espírito do povo e o lamento pelo destino trágico a que esse povo estava fadado. A única solução possível para esse conjunto de demandas idealmente incompatíveis não poderia ser outra senão aquela utilizada por Macpherson: a fraude. Ao renunciar à autoria de Fingal e Temora, Macpherson pôde fazer explodir o lírico no interior desses dois épicos, convertendo o ato de recusar-se em tomar parte do mundo hostil - que é o traço distintivo da lírica ${ }^{19}$ - como elemento definidor do sentido total da ação da narrativa. Como bem observou Matthew Arnold, Macpherson toma de empréstimo o titanismo do Satã miltônico (i.e., a ideia de que uma natureza primeva, em razão de sua pureza original, não pode tolerar as mudanças do mundo e, por isso, prefere a morte a submeter-se ao devir $)^{20}$ e expande-o a todo povo celta. ${ }^{21}$ Configura-se uma realidade aventurosa e vasta, mas que se encontra irremediavelmente apartada do tempo presente, sendo acessível apenas por meio de fragmentárias recordações.

Desde cedo, os modos ossiânicos foram incorporados ao repertório de escritores inclinados às causas de emancipação - ou afirmação - nacional, numerosos em locais de ordem social instável, como na França revolucionária, Rússia, principados alemães ou ex-colônias americanas. ${ }^{22}$ Tratados por muitos - às vezes até de maneira um tanto obstinada - como relatos históricos (até mesmo o cauteloso Gibbon os utilizaria como fonte de informação), os Poemas de Ossian informavam ao leitor de países periféricos a possibilidade de existência de uma cultura vigorosa mesmo entre um povo iletrado e politicamente insignificante.

${ }^{19}$ ADORNO, T. Palestra sobre Lírica e Sociedade. In: Notas de Literatura I. Tradução de Jorge de Almeida. São Paulo: Duas Cidades/ 34, 2006, p. 69.

20 "Farewel ye happy Fields /Where Joy for ever dwells: Hail horrours, hail/ Infernal world, and thou profoundest Hell/ Receive thy new Possessor: One who brings / A mind not to be chang'd by Place or Time." (grifo meu) MILTON, J. Paradise Lost. In: Great Books of the Western World: 32. John Milton. Chicago, London and Toronto: Encyclopaedia Britannica, s.d., p. 99.

${ }^{21}$ ARNOLD, M. On the Study of Celtic Literature. New York: Macmillan, 1904, p.115-6.

${ }^{22}$ Para um panorama da recepção do Ossian na literatura europeia, veja-se GASKILL, H (ed.). The Reception of Ossian in Europe. London: Continuum International, passim. 
O folclore, os mitos e as lendas passaram a ser vistos como elementos definidores de dignidade, respeitabilidade e, sobretudo, independência de uma tradição cultural. Assim, a exemplo de Macpherson, inúmeros estudiosos saíram à procura de épicos perdidos, lendas e baladas populares. E, também como fizera seu predecessor, muitos desses estudiosos iriam interpolar, editar e suprimir variantes do material que encontravam, de modo que melhor se ajustasse às expectativas de sua audiência. ${ }^{23}$

Como já se disse acima, essa reinterpretação da própria cultura em seu estado selvagem por intermédio dos temas e convenções ossiânicas ocorreu de maneira muito fecunda no continente americano. ${ }^{24}$ Empenhadas em constituir uma civilização cultural e artisticamente autônoma em face de suas antigas metrópoles europeias, as literaturas americanas tiveram de voltar-se à herança exclusiva de seus nacionais. Alheias às minúcias dos debates intelectuais de além-mar, os arquétipos ossiânicos seriam seu maior e, talvez, mais eficiente instrumento de conciliação entre os preceitos estéticos da época, de vocação romântica, e a necessidade de afirmação do suposto espírito nacional.

Tal interferência da literatura escocesa nas letras americanas não ocorreu, todavia, de maneira linear e invariável. O primitivismo ossiânico sofreu enormes adaptações ao aportar nestas praias. Suas teses não foram interpretadas de modo uniforme, e perderam sua organicidade; fragmentaram-se em múltiplas sugestões, reorganizadas sob novas premissas e novos propósitos. Abandonar-se-ia, assim, o lamento sobre a passagem do tempo em prol da celebração do novo, porque puro, imaculado, insubmisso e original. A chamada literatura primitivista do continente americano será voltada, via de regra, ${ }^{25}$ ao futuro, prospectiva, e essencialmente otimista.

A relação entre o ossianismo e as obras em que se faz presente é, por conseguinte, meramente temática ou, no máximo, estilística. Em nenhum outro lugar, o primitivismo se constituiu, como nos Poemas de Ossian, em uma forma literária autônoma. Não mais se cogitou de uma conciliação entre a épica e a lírica, como a realizada por Macpherson: as circunstâncias, muito provavelmente, não demandaram tamanho empreendimento, ou talvez as suspeitas (ainda que tardias) de fraude tornassem o feito irrepetível. Assim, os modos primitivistas ou voltaram a ser tratados pela lírica (Chatterton, Walt Whitman, Lord Tennyson) ou foram incorporados ao romance (Mackenzie, Chateaubriand, Scott), gênero que ainda se

${ }^{23}$ Ver McKEAN, T. The Fieldwork Legacy of James Macpherson. Journal of American Folklore, v. 114, n. 454, p. 447-63, mar. 2001 e PORTER, J. "Bring me the Head of James Macpherson": the Execution of Ossian and the Wellsprings of Folkloristic Discourse. Journal of American Folklore, v. 114, n. 454, p. 396-435, mar. 2001.

${ }^{24}$ Ver AGUIAR, O.B. Ossian no Brasil. Goiânia: Universidade Federal de Goiás, 1999, passim; CARPENTER, F. The Vogue of Ossian in America: A Study in Taste. American Literature, v. 2, n. 4, p. 405-17, jan. 1931 e MONTIEL, I. Ossian en la Literatura Argentina. Revista Interamericana de Bibliografía, v. 19, n. 2, p. 146-79, abril-junho 1969.

${ }^{25}$ Algumas exceções óbvias: Os Timbiras, de Gonçalves Dias, e O Último dos Moicanos, de Fenimore Cooper. 
encontrava em estágio de formação ao tempo de Macpherson. Com isso, submetem-se aos limites e convenções desses dois gêneros.

Todavia, mesmo em obras em que o elemento ossiânico é evidente, como em Iracema, de José de Alencar, não se tem o hibridismo de gêneros que se tem no Fingal. Com efeito, conquanto Iracema seja escrita numa prosa poética (o que não quer dizer que seja um poema em prosa) e, com isso, haja enorme ênfase na linguagem, seu elemento lírico não é dotado de autonomia suficiente para transfigurar o modo narrativo: antes, está ao seu serviço e é por ele controlado. Aqui, a linguagem não determina a história nem lhe atribui sentido. Ao contrário do que ocorre nos Poemas de Ossian, há um tempo, um espaço e uma ação muito bem demarcados: perfaz-se um conjunto de procedimentos que criam no leitor a ilusão de que há uma experiência (ainda que um tanto afetada) da realidade sendo narrada. ${ }^{26}$ Para o ossianismo, experiência e realidade são entidades que não chegam - ou mal chegam - a se configurar.

[O presente ensaio foi apresentado como trabalho final da disciplina "Teoria Crítica e Literatura", ministrada pelo Prof. Dr. Jorge de Almeida, no segundo semestre de 2007. Ademais, tem por base as pesquisas destinadas à preparação da Dissertação de Mestrado do autor.]

${ }^{26}$ Sobre o conjunto de procedimentos denominado realismo formal, ver WATT, I. A Ascensão do Romance. Trad. de Hildegard Feist. São Paulo: Companhia das Letras, 2007, p. 30-3. 